\title{
Enunciación
}

http://revistas.udistrital.edu.co/ojs/index.php/enunc

DOI: http://dx.doi.org/10.14483/udistrital.jour.enunc.2016.2.a03

enunciación

Artículo de REFLEXIÓN

\section{De las exigencias genéricas a la emergencia del texto literario: el problema de los géneros}

\section{From generic demands to the emergency of literary text: The problem of genres}

\author{
Nicolás Camilo Forero Olaya ${ }^{1}$
}

Para citar este artículo: Forero, N. C. (2016). De las exigencias genéricas a la emergencia del texto literario: el problema de los géneros. Enunciación, 21(2) 212-225.

Recibido: 29-abril-2016 / Aprobado: 12-diciembre-2016

\section{Resumen}

El presente artículo propone un modelo teórico-metodológico, a partir de los estudios del discurso, que permita eliminar las tensiones que en la teoría de los géneros literarios se ha generado entre el estudio de los géneros denominados naturales y el de los denominados históricos. Para esto, se presenta dicha tensión así como las perspectivas empleadas para la elaboración del modelo (perspectiva sociocomunicativa de Patrick Charaudeau, 2012, y la perspectiva fundada en las prácticas sociales de Isolda Carranza, 2012), desde las cuales los conceptos de situación de comunicación, exigencias y entextualización contribuyen a dicha elaboración. Se concluye que las exigencias que cada género formula para el autor definen tanto los elementos que del género natural se escogen para la realización del texto literario concreto, como las aportaciones que el autor realiza, de acuerdo con un entorno social y literario concreto.

Palabras clave: análisis del discurso, autor, contexto, géneros literarios, texto.

\begin{abstract}
This article presents a theoretical and methodological model, based on Discourse Studies, which allows to eliminate tensions that has been generated between the study of the so-called "natural" genres and the study of the so-called "historical" genres in Literary Genre's Theory. To this end, the tension is examined as well as different perspectives used for the constitution of the model (Socio-communicative perspective from Patrick Charadeau (2012), and the perspective based on social practices from Isolda Carranza (2012)), from which the concepts of situation of communication, demands and entextualization contribute to such effect. It is conclude that the demands that each genre formula sets for the author, determine both the elements that the natural genre are chosen for the realization of the literary text and the contributions that the author makes, in accordance with a social environment and literary environment.
\end{abstract}

Keywords: author, context, discourse analysis, literary genres, text.

1 Estudiante de Licenciatura en Humanidades y Lengua Castellana de la Universidad Distrital Francisco José de Caldas, Bogotá (Colombia). Correo electrónico: nico.c.forero.o@gmail.com 


\section{INTRODUCCIÓN}

En la teoría de los géneros literarios, surgió durante el siglo XX la tensión entre el estudio de los géneros a un nivel puramente teórico y otro a un nivel empírico. La primera perspectiva, como señalan García Berrío y Huerta Calvo (1992), tiene una larga tradición, cuya partida se remonta a la antigüedad clásica, y consiste en estudiar los tres géneros clásicos: lírica, drama y épica. Por el contrario, la segunda perspectiva aboga por no emplear esta clasificación y sí estudiar la obra concreta. Estas perspectivas son la base de los estudios más recientes, centrados en la idea de lo posmoderno (Piña, 2013). Sin embargo, García Berrío y Huerta Calvo sostienen que un estudio completo de los géneros debe tomar ambas perspectivas: para ellos, un estudio histórico del texto literario se direcciona hacia $-y$ está relacionado con- un estudio teórico.

La tarea que se desprende, entonces, es elaborar un modelo que permita desarrollar un estudio de doble vía, que comprenda del fenómeno literario sus constantes transhistóricas y sus variaciones históricas. Desde el análisis del discurso (AD) nos hemos planteado la pregunta de si los actuales estudios de los géneros discursivos -la perspectiva sociocomunicativa de Patrick Charaudeau (2012) y la fundada en las prácticas sociales de Isolda Carranza (2012)- contribuyen a elaborar dicho modelo y de qué manera lo harían, teniendo en cuenta que su procedencia y objetos de estudio son distintos. En tal sentido, este texto presenta, en primer lugar, una síntesis del problema del estudio de los géneros literarios; segundo, expone las perspectivas de los estudios de los géneros discursivos, argumentando por qué estas pueden ser aplicadas a la teoría de los géneros literarios. Por último, señala las consecuencias teóricas que constituyen el modelo esperado, junto con un breve esbozo metodológico.

\section{GÉNEROS NATURALES Y GÉNEROS HISTÓRICOS}

La distinción entre géneros naturales y géneros históricos fue propuesta por Todorov (1988) -que él llama, respectivamente formas "naturales" de la poesía y formas convencionales (p. 37)- y se refieren a dos realidades distintas pero estrechamente vinculadas entre sí. Las primeras formas se refieren a actos del lenguaje, a categorías universalizantes que permiten agrupar las diferentes manifestaciones literarias. Por el contrario, las formas históricas o convencionales son las manifestaciones concretas, de clara comprobación empírica y que no pueden generalizarse. En palabras de Todorov (1988), las formas naturales refieren a "las manifestaciones posibles del discurso, y no las manifestaciones reales de los discursos" (p. 37).

Para entender esta tensión entre estos conceptos $y$, precisamente, entre la elección de una manifestación u otra, recordemos brevemente lo que se ha apuntado sobre estas nociones en la tradición de los estudios literarios.

\section{Lírica, épica y drama}

Estos tres géneros se han tomado como los géneros naturales, las formas en que se han dado a llamar los moldes más generales de producción literaria que, en un registro más contemporáneo, se denominan respectivamente poéticos, narrativos y teatrales (García y Huerta, 1992). La idea de que estos géneros son las categorías más generales de clasificación tiene origen con Platón y Aristóteles. La tradición que surge de estos dos pensadores llegará hasta el Romanticismo, particularmente hasta Hegel, como una perspectiva basada en las modalidades expresivas, y que se resume del modo siguiente: la lírica se entiende como las creaciones en las que el poeta, él solo, habla; el drama, en las que el poeta calla y deja que otros hablen; y la épica, un género mixto, en las que las voces del poeta y el del otro aparecen juntas. 
Hegel, quien asimila esa tradición, no se basará en las voces sino en el elemento referido por el autor y la relación de este con lo referido en el enunciado. En otras palabras, Hegel propone una dialéctica entre

[...] la realidad íntima del ser humano, como ámbito generador de la transfiguración simbolizadora de la poesía, y la realidad exterior de los objetos y las representaciones, donde radican las dos polaridades cuya focalización enfática facultativa puede determinar respectivamente la tesis -lírica-y la antítesis -épica- de un despliegue de los géneros como formas literarias de representación (citado por García y Huerta, 1992, pp. 31-32).

Como es de esperarse, la síntesis consiguiente es el drama, que soportaría dentro de sí las dos realidades que se simbolizan en las otras formas literarias.

En el siglo XX, por el contrario, las teorías basadas en esa tradición proponen la distinción de los géneros mediante un despliegue dialéctico entre identidad y alteridad, entendiendo la literatura como una forma de inquisición de la realidad, semejante al conocimiento científico (García y Huerta, 1992, p. 53). Así, las formas literarias serían: la lírica, un proceso de inquisición vía la identidad, el reconocimiento de sí, mientras que el drama sería el de la alteridad; la épica, o género narrativo, sería la síntesis de estas dos experiencias. Con esta última anotación, se logra que los géneros teóricos o naturales se consideren modos en que se produce el discurso literario, independiente de convenciones y el azar histórico (García y Huerta, 1992).

Sin embargo, el reconocimiento de las diversas manifestaciones producidas en la literatura ubica la atención en el estudio de las formas convencionales, rechazando las formas naturales por considerarlas limitadoras de la creación artística. Entre las voces a favor de esta tendencia se encuentra la de Maurice Blanchot quien, como anota Todorov (1988),
Con más rotundidad que nadie, [...] ha dicho lo que otros no osaban pensar o no sabían formular: no existe hoy ningún intermediario entre la obra singular y concreta, y la literatura entera, género último; no existe, porque la evolución de la literatura moderna consiste precisamente en hacer de cada obra una interrogación sobre el ser mismo de la literatura (pp. 31-32).

Las causas de este pensamiento, García y Huerta (1992) las hayan en los siguientes tres elementos: a) entender la naturaleza cambiante de la literatura; b) el hecho de seguir las ideas de Aristóteles, quien propuso estudios empíricos; y, c) el rechazo sistemático de toda pretención teórica que presuponiera la existencia de categorías naturales o apriorísticas a la creación literaria.

De cualquier forma, creemos que estas ideas no logran ser incompatibles con la idea de los géneros naturales, bien porque no pudieran existir de manera concreta o porque fueran casillas que invisibilizaran la complejidad de las obras singulares y que, a su vez, no pudieran agruparlas. Todorov (1988), al reconocer que hay diversas transformaciones en la literatura, asegura que el hecho de que una obra transgreda una regla no niega el hecho de su existencia; antes bien, la ratifica (p. 33). García y Huerta (1992), por su parte, llevan más lejos este hecho al asegurar que "la taxonomía 'natural' y clásica de los géneros es solo un principio sólido y que puede dar con ello excelentes resultados para examinar 'diferencialmente' las innovaciones y modificaciones de las clases y formas históricas" (p. 50); esto es, se acepta la existencia de las formas naturales y su relación con las formas históricas en términos de entender estas como actualización de las primeras. En tal sentido, resultan ilustrativas las diferentes denominaciones que estos dos autores atribuyen a los géneros naturales: esquemas básicos, actitudes básicas, formas simples.

Hace falta un modelo, entonces, que permita explicitar cómo estos puntos de partida se vinculan con los textos concretos; o, en otras palabras, un modelo que explicite la forma en que los géneros 
naturales "resultan manipulados por la conciencia estilística de determinados escritores" (Sklovski, 1959, citado por García y Huerta, 1992, p. 130). Un modelo semejante tendría en cuenta, por una parte, las convenciones de los géneros naturales, los conocimientos necesarios para realizarlos $y$, por otra, las características de la conciencia estilística que, determinada por una situación histórica concreta, actualiza las formas naturales, en términos de su poética particular y el propósito de su actividad artística. En pocas palabras, el modelo necesitaría dar cuenta de las relaciones entre el género, el texto, el autor y el contexto.

Estos conceptos constituyen un marco proveniente de los estudios del discurso y es nuestro propósito emplearlos para solucionar el problema planteado. En ese sentido, en los siguiente apartados nos encargaremos de mostrar las perspectivas que se emplearán para la elaboración del modelo, así como las modificaciones que deben realizarse para su aplicación en la literatura, teniendo en cuenta la particularidad de esta actividad del lenguaje. El orden de la presentación será el siguiente: primero, traslado de lo no literario a lo literario; segundo, las dos perspectivas de los géneros discursivos; tercero, conjunción de las perspectivas y modificaciones consiguientes para su aplicación al terreno literario.

\section{LOS ESTUDIOS DEL DISCURSO: UNA MIRADA NECESARIA}

Una de las razones por las que consideramos que los ED pueden estudiar la literatura es que esta puede entenderse como una forma más del discurso y que las nociones que de discurso se han propuesto en los ED se le pueden aplicar. Veamos dos definiciones. La primera, por ejemplo, entiende el discurso como toda aquella emisión que "interpretamos al ver o escuchar una emisión" (Van Dijk, 2010, p. 20). En la segunda, por su parte, "hablar de discurso es, ante todo, hablar de una práctica social, de una forma de acción entre las personas que se articula a partir del uso lingüístico contextualizado, ya sea oral o escrito" (Calsamiglia y Tusón, 2002, p. 15). Como vemos, cualquiera de estas definiciones aplica a la literatura: esta es tanto una forma que interpretamos mediante una emisión, para su caso una forma de comunicación escrita, como una acción que se lleva cabo mediante el uso de la lengua, dentro de un contexto específico, en una relación distante entre sus participantes.

Sin embargo, y pese a las coincidencias, hay elementos del discurso literario que hacen que autores como Charaudeau -autor que hemos elegido- no admitan sus propuestas de análisis de discurso como aplicables a la literatura. Charaudeau considera al estudio de los géneros literarios y al de los no literarios como ámbitos inconciliables y, a su vez, recomienda alejarse de la tradición de la teoría literaria cuando de estudiar los géneros discursivos se refiere. Esto es así porque,

[...] en el fondo, en el ámbito de la poética, es siempre la singularidad del texto lo que se persigue, tanto por parte del escritor como del analista. El género literario no es más que una reconstrucción a posteriori, mientras que, en el ámbito no literario, el género es una necesidad primera, puesto que el hablante se construye como sujeto en ese marco (Charaudeau, 2012, p. 21).

Frente a esto, queremos discernir afirmando que los géneros literarios y los no literarios son ambos, a la vez, construcciones tanto previas como posteriores y que son marcos que permiten la construcción de los individuos en sujetos. En primer lugar, aceptamos que la creación literaria lleva dentro de sí la pulsión de innovación y que las obras canónicas ${ }^{2}$

2 Hacemos referencia a las obras que se convierten en importantes debido a su posterior influencia sobre la obra de autores también posteriores. Como dice Bloom (2015), se trata de obras que poseen una extrañeza, "una forma de singularidad que o bien no puede ser asimilada o bien nos asimila de tal modo que dejamos de verla como extraña" (p. 13). Esta asimilación -que llevan a cabo los lectores y escritores futuros y se condensa en sus obras- posiciona a la obra predecesora en el canon (esto es, en "lo que se ha conservado de entre todo lo que se ha escrito")" (Bloom, 2015, p. 27). 
constituyen algo innovador, lo que no invalida la idea de que los géneros sean elementos previos al texto. Como reconoce el mismo Charaudeau (2012), la tradición literaria ha enseñado que los géneros deben entenderse como "categorías que sirven de modelo o de contramodelo de producción y de lectura de los discursos" (p. 22), esto es, elementos previos y posteriores al acto de producción de texto.

A este respecto, conviene recordar la hipótesis según la cual el género no es inmanente al texto (hipótesis desarrollada por Carranza, 2012), por cuanto este es la realización concreta de las convenciones genéricas y no el género al que pertenece. Esta idea permite recordarnos que el texto literario constituye una construcción posterior al género, ya que este lo constituyen las convenciones que contribuyeron a producirlo, pero también nos permiten entender la posibilidad de que el texto, de llegar a ser innovador, podría convertirse en nuevas convenciones genéricas para las posteriores generaciones de escritores, con lo que el género literario sería, en este caso, una construcción a posteriori. En todo caso, es una cuestión de perspectiva.

En segundo lugar, sobre la idea de que los géneros no literarios permiten la construcción de los sujetos en tanto marcos, podemos decir que no hay una diferencia radical respecto al proceder de los géneros literarios. Si los géneros no literarios construyen en sujeto al hablante lo hacen de una manera simultánea al acto de proferir el discurso, pues con ello el hablante asume un rol, una identidad y unas particulares maneras de crear el discurso, de acuerdo con un determinado ámbito de práctica social (Charaudeau, 2012). Por el contrario, en los géneros literarios el autor -hablanteno goza de esa construcción de sujeto simultánea al acto de decir: por una parte, la materialidad de la literatura (principalmente medio escrito) no lo permite $y$, de otra, el mismo proceder de la tradición literaria, tal como lo explicamos a través del concepto de canon, retarda esta construcción. Por su materialidad, el autor solamente puede ser reconocido como tal, luego de haber producido el texto concreto y de que este haya sido difundido y leído; pero por su singularidad, el reconocimiento como autor -y autor canónico- solo puede darse después de varios años cuando posteriores generaciones de autores demuestren su importancia. En otras palabras, los géneros literarios también constituyen marcos de elaboración del sujeto en donde este es una construcción posterior al acto de decir.

En este punto, creemos que considerar la literatura como una práctica de lenguaje (discurso) y los géneros como construcciones tanto previas como posteriores, y considerarlos también como espacios para la construcción a posteriori del sujeto que los reconstruye, nos parecen argumentos suficientes para trabajar los géneros literarios desde las perspectivas de los ED. Estas perspectivas, las presentamos a continuación.

\section{La perspectiva sociocomunicativa}

La noción que el autor de esta perspectiva (Charaudeau, 2012) maneja de los géneros no se diferencia radicalmente de la que anteriormente diera Bajtín (1999), quien los entendía como un conjunto de enunciados de características determinadas asociados a "las esferas de la actividad humana". Charaudeau (2012), por su parte, demuestra que ni las propiedades formales, ni las discursivas, ni las funciones del lenguaje son criterios válidos para caracterizar y estudiar los géneros, y por ello, prefiere abordar la cuestión

[...] desde el otro lado de la lupa. Ya no se trata de partir de las configuraciones textuales ni de los procedimientos de puesta en escena del discurso, sino de hacerlo desde los diferentes ámbitos de la práctica social que se instaura en una sociedad, para luego observar cómo las prácticas lingüísticas se vinculan con ellos (p. 28).

De lo anterior, se sobreentiende la definición de género discursivo como una práctica lingüística asociada -o vinculada- a un ámbito de práctica 
social. A Charaudeau le interesa explicar cómo estos ámbitos de práctica determinan las características de las prácticas de lenguaje, tanto a nivel discursivo como formal. El punto de partida de esta propuesta es la hipótesis de que cada ámbito "tiende a regular sus intercambios y, como consecuencia de ello, a instaurar regularidades discursivas" (p. 29). Por ello, Charaudeau propone abordar una teoría de la situación comunicativa como base para la elaboración de un modelo que permita la caracterización y estudio de los géneros.

Dicha teoría entiende la situación como el ámbito de práctica social convertido en

[...] ámbito de intercambio comunicacional. [...] donde los actores sociales se constituyen en instancias de comunicación, alrededor de un dispositivo que determina su identidad, la (o las) finalidad(es) que se instauran entre ellas y el ámbito temático que constituye su basamento semántico (p. 31).

Cada una de estas propiedades (finalidad, identidad, ámbito temático y disposición material) vienen a determinar las propiedades, respectivamente, del discurso (modos de organización del discurso, modos enunciativos, modos de tematización y modos de semiologización). Estas, a su vez, determinan las características formales (léxico, gramática, fraseología) que, en este punto, son una elaboración tanto social como individual (p. 38). A esto último se debe la diferenciación entre un texto y otro construido dentro de un mismo género.

Sin embargo, la situación de comunicación no basta por sí sola para entender las propiedades de los géneros. Así, Charaudeau (2012), para responder a la pregunta por la distinción entre géneros discursivos y subgéneros discursivos, propone una estructuración de la situación de comunicación en dos grados: por una parte, la situación global de comunicación (SGC) donde se disponen, conceptualmente, los elementos que la integran; de otra, la situación específica de comunicación (SEC) donde se disponen los elementos que integran la situación pero de manera concreta. Así, para este autor, a la SGC corresponderían los géneros (discursos políticos, discursos mediáticos) y a la SEC correspondería los subgéneros (noticia, debate, mitin, entre otros).

Para terminar esta sección, destacamos de esta perspectiva, primero, el resaltar el anclaje social del discurso y los géneros; segundo, el entender los géneros como una combinación de elementos situacionales, discursivos y formales (Charaudeau, 2012, p. 38); y tercero, el exponer el discurso como una producción tanto social como individual.

\section{La perspectiva fundada en las prácticas} Isolda Carranza (2012), por su parte, no plantea una teoría de la situación comunicativa sino que, a partir de la sociología de la práctica y de la corriente crítica del análisis del discurso, presenta los géneros como recursos sociales, como marcos que permiten entender las prácticas discursivas. Su propuesta concibe al género como algo no inmanente al texto y "por lo tanto, no lo reduce a un tipo de texto, ni a esquemas, etapas o un componente del sistema lingüístico, sino que tiene en cuenta su asociación con un tipo de actividad" (Carranza, 2012, pp. 99-100). Así, su enfoque presta atención al aspecto accional del género junto con los participantes y "los acontecimientos en los que se inscriben los intercambios verbales" (p. 100).

Asimismo, esta autora concibe a los hablantes como agentes sociales ya que son individuos que no están determinados totalmente por el sistema lingüístico y, por ello, tienen posibilidades de modificar la manera en que se produce un texto obedeciendo o no las convenciones genéricas. Carranza (2012) demuestra esto mediante los resultados de su investigación en los tribunales argentinos, donde constató que los hablantes, de acuerdo con su identidad, prestigio o autoridad, podían introducir elementos en la elaboración textual que no eran propios del género: "Algunos actores sociales individuales movilizan recursos de su repertorio discursivo, aprovechan el potencial en la configuración del género y producen textos con rasgos poco convencionales, que a la 
vez son interpretables como indicios de su posicionamiento y construcción identitaria" (p. 110).

Con lo anterior, se entienden los géneros como marcos flexibles -y no normas restrictivas, rígidasque pueden ser manipuladas por el hablante y dar lugar a textos muy diversos. Todo esto se explica por la libertad del hablante y queda perfectamente explicado en el proceso que Carranza (2012) denomina entextualización: es decir, "la articulación entre las convenciones genéricas y la emergencia del texto a partir del contexto situacional, el cual incluye a los actores, sus acciones y los entornos sociales y espacio-temporales" (p. 109). De manera que para entender el modo en que se producen los textos es preciso estudiarlo no solo en relación a las convenciones genéricas sino también en relación a los participantes y los diversos entornos en que interactúan.

De esta propuesta, interesa destacar, primero, el papel protagónico que tiene "el sujeto que ocupa la posición de productor textual" (Carranza, 2012, p. 113) en la elaboración del texto; segundo, entender el género como marco flexible sujeto a la modificaciones del hablante de acuerdo con el entorno -clave si queremos relacionar las formas naturales con las formas históricas, por cuanto estas últimas son producto de la manipulación-; tercero, el concepto de entextualización que sistematiza este proceso de relacionamiento (sujeto-entorno-texto); y, por último, destacamos el concepto de exigencias que, si bien la autora lo nombra para decir que "el género 'alegato' define exigencias específicas para el sujeto que ocupa la posición de productor textual" (Carranza, 2012, p. 113) sin explicarlo a cabalidad, lo consideramos necesario y útil, como más adelante veremos, para entender el proceso de creación del discurso literario en relación a los géneros.

\section{LOS GÉNEROS Y EL DISCURSO LITERARIO: LAS EXIGENCIAS}

Ahora, la tarea que debemos realizar, para lograr la interrelación entre las formas naturales y las formas históricas de la literatura, es examinar la literatura como práctica de discurso independiente, describiendo sus gradaciones genéricas naturales, hasta llegar a las manifestaciones concretas, es decir, los textos que los autores elaboran y los lectores leen. Como se verá, este proceso conlleva modificaciones para las perspectivas de los ED.

\section{El problema del traslado}

Al intentar aplicar la perspectiva sociocomunicativa de Charaudeau, particularmente en la identificación de la situación comunicativa, sus gradaciones y correspondencia con géneros, nos encontramos con la siguiente dificultad: si intentamos asociar una situación global de comunicación de la literatura, encontraríamos que la literatura, el discurso literario, consistiría en el género en un nivel conceptual general. Esto resulta inapropiado ya que los géneros literarios son otros: los que se han nombrado naturales. Por otra parte, si ubicáramos los géneros naturales en relación con una situación específica de comunicación, estos se categorizarían como subgéneros, dejando fuera del espectro las manifestaciones menos abstractas como los subgéneros literarios (soneto, oda, verso libre, etc.). En otras palabras, tenemos tres categorías -discurso literario, géneros literarios, subgéneros literarios- que no logramos ubicar en la estructuración que Charaudeau plantea de la situación de la comunicación.

Por lo anterior, preguntamos: ¿Deben las gradaciones genéricas del discurso literario ajustarse a la estructuración que Charaudeau propone de la situación comunicativa o, por el contrario, dicha estructuración de la situación de comunicación no es adecuada a las gradaciones del discurso literario y es necesario, por tanto, una modificación? Nosotros preferimos esta segunda alternativa dado que hay más certeza sobre las categorías genéricas de la literatura -según la tradición- y son menos los indicios sobre una situación comunicativa. Corresponde examinar, por tanto, en qué nivel se encuentra la situación de comunicación que falta para relacionar los tres niveles del discurso 
literario, al tiempo que se reconocen las propiedades de cada uno de estos niveles.

Situación global de comunicación literaria (SGCL): lo supragenérico

En el nivel más alto de abstracción ubicamos el discurso literario como una categoría supragenérica, ya que agrupa producciones discursivas que se diferencian de otras formas que se consideran no literarias. De esta manera, podemos ubicar los otros niveles de gradación genérica de la literatura: los géneros y los subgéneros. A su vez, entenderíamos la situación global como el ámbito social de práctica literaria, asumiendo la literatura como una actividad que, prácticamente, se lleva acabo solo con el lenguaje. La pregunta que se debe plantear antes de definir esta situación comunicativa y que, sin embargo, no podemos responder -bien porque no es nuestro propósito, bien porque es una tarea difícil- es la siguiente: ¿Qué podemos entender por el discurso literario y qué lo caracteriza?

Al respecto, conviene recordar las anotaciones de Jonathan Culler sobre el discurso literario. Si bien, dice, se han adjudicado valores intrínsecos a la literatura, como que ella trae a primer plano el lenguaje, que lo integra, que es ficción, que es un objeto estético y de constante autorreflexión e intertextualidad, muchas de esta propiedades forman parte de otras actividades del lenguaje y, muchas veces, lo que define lo literario no son solamente las propiedades de los discursos allí producidos, sino una mirada concreta que una cultura y un tiempo determinados hacen sobre los textos (cfr. Culler, 2004, pp. 29-55). En otras palabras, lo literario se puede encontrar tanto en las obras literarias mismas como en la mirada que sobre ellas se aplique, razón por la cual dar una definición a la literatura y atribuirle características precisas resultaría un ejercicio arbitrario. Es más conveniente, agrega Culler (2004),

Pensar [que] la literariedad [...] es mantener ante nosotros, como recursos para el análisis de esos discursos, ciertas prácticas que la literatura suscita: la suspensión de las exigencias de la inteligibilidad inmediata, la reflexión sobre qué implican nuestros medios de expresión y la atención a cómo se producen los significados y el placer (p. 55).

En ese sentido, una SGCL tendría como objetivo producir discursos que, acomodados a parámetros institucionales que definen lo literario según una época concreta, lleven a una reflexión sobre el significado, generen la suspensión de las exigencias de inteligibilidad inmediata, produzcan placer y, lo más importante, Ilamen la atención por su carácter innovador, porque también lo literario, como dice Bloom (2015)

[...] no es simplemente lenguaje; es también voluntad de figuración, el objetivo de la metáfora que Nietzsche una vez definió como el deseo de ser diferente, $[\ldots]$ ser distinto de las metáforas e imágenes de las obras contingentes que son el patrimonio de uno (p. 22).

Por otra parte, una situación de comunicación semejante tendría como participantes un autor, en posición de sujeto productor de discurso, y un público constituido por otros autores, críticos literarios y el público en general. Asimismo, esta situación se daría en un entorno social determinado, en una locación concreta y en un entorno artístico, específicamente literario, que configura las convenciones literarias del momento. La importancia de estos dos últimos elementos en la configuración última del texto es decisiva, como se verá cuando hablemos de las exigencias genéricas y el proceso de entextualización.

Situación intermedia de comunicación literaria (SICL): los géneros

En este nivel de la comunicación literaria, ubicamos lo que la teoría denomina géneros naturales o teóricos. Esta situación constituye el espacio en el que se encuentran las tres grandes modalidades del discurso literario -poesía, narrativa y teatro- entre las cuales el autor escoge para llevar a término el 
objetivo propuesto en la SGCL. A su vez, cada una de estas modalidades propone para el autor unas exigencias específicas. Así, si un autor se decidiera por poesía lírica, deberá acogerse a las implicaciones de un género que tiene por objeto satisfacer la necesidad "de expresar lo que sentimos y contemplamos a nosotros mismos en la manifestación de nuestros sentimientos, [pero también de ofrecer] lo que hay de más elevado y más profundo en las creencias, en la imaginación y en los conocimientos de un pueblo" (Hegel, 1871-20, citado por García y Huerta, 1992 p. 151). Todos sus esfuerzos de lenguaje -elaboración de imagen y ritmo- deben encaminarse en este objetivo $y$, teniendo en cuenta al destinatario, deberán también lograr que este se sienta identificado, en términos de empatía o simpatía (p. 79).

Sin embargo, estos procedimientos no son del todo independientes en algunas manifestaciones concretas de la literatura: los géneros del discurso literario tienden a cruzarse y a construir formas híbridas que dificultan la compresión de los géneros literarios como realidades aisladas. Este fenómeno queda representado en el modelo que García y Huerta (1992) sugieren, modelo que proponen Eduard von Hartman y Abert Guérard, donde se encuentran las diferentes posibilidades de hibridación:

a) Lírica
a. Lírica-lírica.
b. Lírica-narrativa.
c. Lírica-teatro.

b) Narrativa
a. Narrativa-narrativa.
b. Narrativa-lírica.
c. Narrativa-teatro.

c) Teatro
a. Teatro-teatro.
b. Teatro-lírica.
c. Teatro-narrativa.

De manera que los autores no solo eligen en esta instancia la modalidad expresiva, sino también si prefieren, o no, hibridar las modalidades expresivas. Esta decisión tendrá mayor o menor materialidad en la elaboración de alguna forma subgenérica -materializada en el texto-, como veremos a continuación.

Situación específica de comunicación literaria (SECL): los subgéneros

Para llegar al texto concreto la producción del discurso literario se encuentra con un nueva subdivisión, que se materializa en la selección que el autor hace de alguna forma subgenérica. Estas formas, que acá entendemos como las diferentes maneras en que se han realizado los géneros naturales a lo largo de la tradición literaria, constituyen el fundamento más próximo a la creación, pues ni es texto ni es género, y contienen la mayor parte de información -instrucciones- sobre cómo elaborar el texto. Para el caso de la poesía lírica -siguiendo con el ejemplo- los subgéneros lo constituirían el soneto, la oda, la elegía, el verso libre, el poema en prosa, entre otros, que pueden manifestar desde un menor a mayor grado de hibridación. El soneto constituiría una forma lírica-lírica, mientras que la balada lírica una forma lírico-narrativa, donde se narra un suceso pero lo que importa en el texto es el tono sentimental que se expresa.

\section{Emergencia del texto: las exigencias genéricas}

Una vez escogida la forma subgenérica hemos ubicado el proceso de producción textual, que es una actividad en la que se articulan no solamente las convenciones de lenguaje presentes y aportadas por la traición, sino las que el autor en su proceso de creación aporta, a partir de su deseo de innovación. Pero la aparición del texto y su diferencia respecto a las formas anteriores no se puede explicar por sí sola, atendiendo al factor único del deseo de innovación y las convenciones dadas por lo subgéneros. Se debe enumerar otros factores que determinan esa trasformación, que son los que en la SGCL nombrábamos anteriormente: el entorno 
literario y el entorno social. Cada uno de estos, no obstante, no ejerce influencia directa sobre el texto sino, como decíamos en la propuesta de Isolda Carranza (2012), a través de las exigencias genéricas.

Si bien la autora no desarrolla este concepto en el texto consultado, sí aclara en qué consiste: cada género discursivo define exigencias para cualquier hablante, como un repertorio verbal adecuado a la situación que se refiere, un control consciente de su discurso, entre otras exigencias. En el caso de la literatura, las exigencias pueden plantearse de manera distinta, atendiendo a las propiedades de esta. En primera lugar, cada uno de los niveles en que se divide la producción literaria ofrece dificultades diversas para el escritor. El más abstracto, el de literatura, ofrece las exigencias más generales y que abarca cualquier producción dentro de ella: entre estas, destacamos las exigencias de conocimiento y uso sobresaliente de una lengua, y las exigencias de innovación, lo cual requiere a su vez un amplio conocimiento tanto de la literatura como de las diversas maneras en que en ella se haya usado una lengua.

En el nivel de los géneros naturales, las exigencias han quedado descritas en términos de lo que debe hacer el autor: un poeta, por ejemplo, debe ser capaz de crear situaciones que recreen un acto de habla concreto (hacer creer que alguien habla), hacer lo imposible -como hablarle al viento-, traer a primer plano los aspectos formales del lenguaje, entre otros elementos (cfr. Culler, 2004, pp. 87-100). En el nivel de los subgéneros, que están más prontos a la producción textual, aparecen exigencias más concretas y no solamente definidas por la tradición literaria sino por el entorno social y artístico en que el autor produce sus discursos. Un autor que decidiera realizar un soneto, no solo se le exige conocer las propiedades temático-formales de esta forma lírica, sino que debe, asimismo, según el entorno artístico -un movimiento literario, como el Modernismo, o una escuela, como el culteranismo dentro del barroquismo- crear unas exigencias para sí que le permitan hacer un soneto de manera distinta.
El entorno social, a su vez, determina las exigencias que al autor se le plantean ya que, si bien la literatura puede considerarse un sistema aislado en términos del manejo del lenguaje a un nivel formal estilístico, algunas determinantes sociales pueden afectar en términos de contenido o temáticos. Es el caso del Modernismo, en cuyo seno los poetas decidieron no hablar de los elementos de la realidad cotidiana -los intentos de modernización en Latinoamérica- ya que esta era rechazada sistemáticamente por ellos. Sus temáticas y fines eran otros:

La difusa conciencia de desajuste y desencanto que impregna la visión del mundo de nuestro Modernismo literario, hace de la Belleza -así, con mayúscula-, la suprema sino la única finalidad del Arte -también con mayúscula-, y convierte a este en una especie de bastión de defensa, oponiendo sus logros y posibilidades a la inanidad de lo real y cotidiano (Osorio, 1988, p. XII).

Por estas razones, consideramos que los factores entorno social y entorno artístico influyen en la obra y, en este modelo, los explicamos a través del concepto de exigencias pero en un nivel más amplio de lo que ha planteado Carranza: las exigencias ya no solo concentran los deberes que un género intrínsecamente prescribe sino que atiende a factores externos a este, como el entorno literario, el entorno social y el autor mismo.

Ahora bien, si aceptamos las exigencias como concepto clave, parece oportuna una distinción entre dos tipos de estas ya que son factores de distinta índole. Para el caso de los factores internos, hablamos de exigencias internas (EI) que entendemos como imperativos de adquisición ya que el autor debe asumir la tradición literaria, particularmente del género y subgénero al cual aplica. En cambio, los factores externos, como el autor, el entorno artístico y social, los entendemos como imperativos de proposición pues son los elementos en cierta manera nuevos y que aportan 
singularidad al texto. Estos, los denominamos exigencias externas (EE).

Lo que estos conceptos finalmente permiten entender es el proceso de entextualización, entendido como actividad previa, pero a la vez simultánea, a la aparición del texto. Recordando la definición que dábamos arriba de entextualización, según Carranza (2012), la literatura participaría de un proceso semejante, salvo por la adición de otros factores. En la entextualización literaria, las convenciones genéricas -que hemos denominado exigencias internas (lo que se ha hecho en la literatura [los géneros y subgéneros] y que el autor debe conocer y estar en capacidad de hacer)- se vincula con lo que el autor debe realizar para hacer de su obra algo diferente de acuerdo a sí mismo y a los entornos en que se encuentra, esto es, según las exigencias externas. En otras palabras, la entextualización literaria es un proceso en el que se vinculan las convenciones literarias (de género y subgénero) con la emergencia del texto concreto, determinado por las exigencias externas que definen una parte de la producción del discurso literario.

Articulación de las formas naturales y las formas históricas

Con los elementos que hemos nombrado hasta aquí, creemos haber logrado la articulación de las formas históricas con las naturales, en la medida en que los niveles supragenéricos, genéricos y subgenéricos se relacionan entre sí (como formas teórico-abstractas) y determinan la producción de los textos literarios concretos (como formas empírico-históricas). La tabla 1 sintetiza este proceso.

\section{ESBOZO METODOLÓGICO}

La investigación que planteamos para el análisis literario tiene por objeto examinar lo que un autor ha hecho para crear un texto innovador, en relación a las formas genéricas. No se trata de una propuesta para descubrir grandes autores sino cómo los que se han consagrado como tal lo han logrado. A continuación, presentamos los momentos y elementos que se tendrían en cuenta para el análisis, presentando ejemplos de la poesía de Anna Ajmátova y los acmeístas.

- Texto: este momento es el concerniente a la lectura con la finalidad de identificar las características sobresalientes de uno o varios textos de un autor. Para esta labor pueden contribuir tanto los comentarios críticos o las reseñas sobre alguna obra en particular como la lectura individual. La finalidad de este momento es la extracción de las categorías que servirán de análisis de la obra, que bien pueden ser, en el caso de la poesía, la

Tabla 1. La emergencia del discurso literario: de los niveles genéricos al texto

\begin{tabular}{ccc}
\hline Situación & Nivel de género & Ejemplo \\
\hline SGCL & Supragenérico & Literario \\
SICL & Genérico (formas teóricas) & Lírico, narrativo o teatral. \\
SECL & Subgenérico ${ }^{3}$ & Soneto, prosa lírica, verso libre, etc. \\
& Entextualización & \\
Situación concreta & Texto (forma histórica) & Soneto realizado por un autor en un \\
& & lugar y tiempo determinados. \\
\hline
\end{tabular}

Fuente: elaboración propia.

3 Estas formas no son teóricas sino formas que, construidas en algún momento de la literatura, aparecen como el repertorio del género mayor y es el elemento de constante transformación. Puede decirse que son propiedades tanto abstractas como históricas. 
métrica, la rima, la construcción de imágenes respecto al tratamiento de un tema, etc. Así, de Ajmátova, hemos sabido que su poesía ha destacado por "su concreción, 'su tono íntimo y su sencillez"' (Myers, 2001a, p. 71), por lo que deberíamos identificar qué elementos de los poemas que ella realizó contribuyen a lograr dichas características. Estos elementos que podemos identificar, los ilustramos más adelante.

- Intertextualidad: con las mismas herramientas del momento anterior, en este se debe acceder a los textos que los del autor analizado evoquen, bien emulándolos o desafiándolos. En este proceso, se debe reconocer cuál de las categorías identificadas en el paso anterior está implicada en la intertextualidad, es decir, si el texto que analizamos revitaliza una metáfora o emplea un tratamiento distinto de un tema, respecto a la manera como los autores o textos que evoca lo hacían. Para el caso de Ajmátova, como también hemos sabido que pertenecía a un movimiento literario (el acmeísmo) que explícitamente se oponía a la poética de los simbolistas rusos (cfr. Myers, 2001b), los nexos que debemos ubicar en este nivel se deben dar entre su obra y la obra simbolista. Esto es, identificar qué elementos decide esta poeta -y quizá su movimiento- transformar de la manera en que los simbolistas hacían poesía.

- Exigencias genéricas internas: en este nivel debemos analizar a fondo las categorías identificadas, pero cómo eran empleadas por los autores precedentes, los que son evocados en el texto que analizamos. Respecto a los simbolistas, sabemos -de acuerdo con Myers- que creían que la poesía era una manera de acceder a una realidad trascedente oculta en la realidad sensible, que era símbolo de esa realidad y creían que ellos eran el médium entre esa realidad y las demás personas (Myers, 2001b, p. 13). Por ello, el yo lírico era un ser humano capaz de esa sabiduría y el léxico empleado en sus poemas estaba marcado por un hálito de misterio. Por ejemplo, en el tema amoroso, el objeto de amor era un ser rodeado de misterio, que aparecía en lugares bohemios y nocturnos (cfr. Myers, 2001b, p. 26). Como vemos, los elementos a analizar son, entre otros: los epítetos empleados para caracterizar lugares y objetos amorosos, los objetos amorosos y los lugares y los epítetos para describir el yo lírico.

- Exigencias genéricas externas: hecho lo anterior, debemos volver al texto o textos que analizamos, los de partida, para ver cómo manejan los elementos antes dichos en su poesía. Continuando con el ejemplo, los acmeístas y Ajmátova tuvieron que buscar una alternativa a dicha forma de hacer poesía, así como un cambio a la manera de concebirla y el papel del poeta en el mundo. Así, para los acmeístas y Ajmátova, la poesía no era ya un conocimiento trascendental oculto detrás de las cosas y el poeta se hacía terrenal, como una persona al mismo nivel de los otros seres humanos (cfr. Myers, 2001b), con lo que las fuentes de inspiración son los elementos más comunes y el aparato lexical se hace más preciso, lejos de los misterios y las tinieblas de los simbolistas. Para ver con mayor detalle estas características, se debe recurrir al análisis de esos elementos, como en el momento anterior.

- Los géneros: pensado como un balance, este último momento debe dar cuenta de las implicaciones de género del análisis textual e intertextual precedente. Por ejemplo, debe preguntarse si estas trasformaciones se dan a nivel de género o subgénero, entre otras preguntas. En el caso de Ajmátova, podríamos decir que las transformaciones que realiza se ubican en un nivel genérico y no subgenérico, pues no hay cambios en la realización de algunas formas poéticas sino en la manera de concebir el género mismo, la poesía y 
su hacer. Esto es así porque, si los futuristas hicieron contra los simbolistas "una rebelión de medios contra medios, el acmeísmo fue una rebelión de esencia contra esencia" (Myers, 2001b, p. 11).

\section{CONCLUSIONES}

Tratar de comprender un discurso como el literario no es una tarea sencilla y lo que se ha pretendido en este documento es proponer una mirada sobre aquel y también un esbozo metodológico para una futura investigación en el terreno, con la intención de estudiar las formas concretas de la literatura sin perder de vista las formas teóricas-naturales. De este recorrido, extraemos las siguientes conclusiones:

- La aplicación de las perspectivas de los ED han servido para detallar elementos de la literatura que de otro modo no hubiéramos encontrado. Primero, prestar atención al texto literario en su contexto, al entorno literario y social así como a su autor, permite identificar elementos que influyen tanto en la emergencia de la obra así como su singularidad. Segundo, se destaca que el discurso literario, al igual que otras formas de discurso, tiene varias subdivisiones y que cada una de ellas implica unas exigencias específicas para la elaboración del texto. Por esta razón, creemos que la reconceptualización que hemos realizado del concepto exigencias resulta fructífera en la medida en que resalta el hecho de que las obras literarias no surgen ex nihilo y requieren una reflexión constante por parte del autor.

- Toda aplicación teórica no puede hacerse sin transformaciones. La perspectiva de Charaudeau, que en principio parecía negarse a la aplicación, ha permitido identificar, primero, el anclaje situacional de la práctica literaria, y segundo, identificar las gradaciones genéricas que se encuentra en esta. Pero, para lograrlo, esta perspectiva tuvo que modificarse: en la exposición hemos visto el surgimiento de una situación comunicativa intermedia. De igual forma, la perspectiva de Carranza, de cuyo marco tomamos entextualización y exigencias genéricas, sufrió modificaciones y dio pie a los conceptos capitales de esta perspectiva: las exigencias que solo fueron en su perspectiva algunos saberes que tuviera un hablante para producir un texto, en la literatura han cobrado una doble dimensión (EI y EE) para contener dentro de sí información sobre cómo hacer un texto y cómo debería hacerse.

- La aplicación de las perspectivas de los géneros discursivos no pretende definir los géneros literarios. Al señalar el proceso mediante el cual, por una parte, el autor se apropia de la tradición y, por otra, incorpora elementos nuevos a esta, se deja entrever la principal funcionalidad de esta propuesta: estudiar las maneras en que la literatura se trasformar (sus géneros, subgéneros) de acuerdo con la acción de los mismos escritores.

- Por último, esta propuesta reitera que la distancia entre las prácticas de lenguaje no literario y el literario no es, en sí, pronunciada como pudiera creerse. Pero, además, reafirma lo siguiente: el discurso literario puede considerarse un punto más en la agenda de los ED. Al tener elementos comunes -situación de comunicación, gradaciones y exigencias genéricas- permite un análisis como el que se haría a cualquier otro discurso: partir de categorías básicas sobre el mismo hasta llegar a un análisis más específico según el espacio social al que se inscriba cada práctica. Por ello, así como en el análisis del discurso educativo se tendría que partir de la lingüística de texto y demás ciencias de lenguaje hasta llegar a teorías sociológicas, psicológicas, entre otras, que expliquen la educación, así debiera 
estudiarse el discurso literario, partiendo de las ciencias del lenguaje hasta llegar a las diferentes teorías literarias que estudien en detalle esta práctica.

\section{RECONOCIMIENTOS}

Este artículo de investigación es un subproducto del proyecto de investigación titulado "Los géneros discursivos en las interacciones cotidianas", desarrollado por el semillero Hermeneia de la Universidad Distrital Francisco José de Caldas, y financiado por el Centro de Investigación y Desarrollo Científico (CIDC) de la misma institución.

\section{REFERENCIAS BIBLIOGRÁFICAS}

Bajtín, M.M. (1999). El problema de los géneros discursivos. En: Estética de la creación verbal (pp. 248293). México: Siglo XXI Editores.

Bloom, H. (2015). El canon occidental. Barcelona, España: Editorial Anagrama.

Calsamiglia, H. y Tusón, A. (2002). Las cosas del decir. Manual de análisis del discurso. Barcelona: Ariel.

Carranza, I. (2012). Los géneros en la vida social: la perspectiva fundada en las prácticas sociales. En: M. Shiro, P. Charaudeau y L. Granato. Los géneros discursivos desde múltiples perspectivas: teoría y análisis (pp. 99-124). Madrid, España: Iberoamericana Vervuert.

Charaudeau, P. (2012). Los géneros: una perspectiva sociocomunicativa. En: M. Shiro, P. Charaudeau y L. Granato. Los géneros discursivos desde múltiples perspectivas: teoría y análisis (pp. 19-44). Madrid, España: Iberoamericana Vervuert.

Culler, J. (2004). Breve introducción a la teoría literaria. Barcelona, España: Crítica.

García B., A. y Huerta C., J. (1992). Los géneros literarios: sistema e historia. Madrid, España: Cátedra.

Myers, D. (ed.) (2001a). Poesía acmeísta rusa. Madrid: Visor.

Myers, D. (2001b). Prólogo. En: Poesía acmeísta rusa (pp. 7-37). Madrid: Visor Libros.

Osorio T. N. (1988). Prólogo. En: Manifiestos, proclamas y polémicas de la vanguardia literaria hispanoamericana. Caracas: Fundación Biblioteca Ayacucho.

Piña, C. (2013). La trayectoria de los géneros literarios en la posmodernidad. Cuadernos del CILHA, 14(19), 11-15. Recuperado el 2 de noviembre de 2015, de https://dialnet.unirioja.es/descarga/articulo/5116648.pdf

Todorov, T. (1988). El origen de los géneros. En: M. Garrido. Teoría de los géneros literarios (pp. 31-48). Madrid, España: Arco Libros S. A.

Van Dijk, T. A. (2010). Estructuras y funciones del discurso. 3a. ed. México: Siglo XXI Editores.

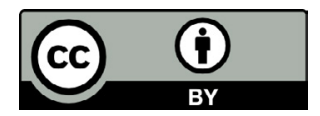

